\title{
Estudo in vitro e ex vivo da ação de diferentes concentrações de extratos de própolis frente aos microrganismos presentes na saliva de humanos
}

\author{
Cinthia Coelho Simões, * Danilo Barral de Araújo, Roberto Paulo Correia de Araújo \\ ${ }^{1}$ Departamento de Biofunção, Instituto de Ciências da Saúde, Universidade Federal da Bahia, \\ Av. Reitor Miguel Calmon, s/n, Vale do Canela, 40110-902 Salvador-BA, Brasil
}

\begin{abstract}
RESUMO: Este estudo avaliou, in vitro e ex vivo, a ação de diferentes concentrações de extratos de própolis, comparativamente à eficácia de anti-sépticos bucais, frente aos microrganismos presentes na saliva de humanos. Para a realização dos ensaios in vitro, foi adicionada à saliva solução de glicose a $25 \%$, seguindo-se da coleta de alíquotas para a preparação dos grupos controle (C) e experimentais, mediante a adição do extrato de própolis a $11 \%, 20 \%$ e $30 \%$, e do Periogard, Listerine, Malvatricin e Parodontax. Nas experimentações ex vivo, foram coletadas amostras de saliva em jejum $(\mathrm{C})$ e após o enxágüe individual com os extratos de própolis, seguindo-se da adição de glicose. Nas duas fases, foram recolhidas alíquotas das misturas e determinado o consumo de glicose pelos microrganismos pelo método Glicose Oxidase, nos tempos 0,24 , $48 \mathrm{~h}$ de incubação a $37^{\circ} \mathrm{C}$. Constatou-se diferenças estatisticamente significantes no consumo de glicose aos serem comparadas as médias do grupo C nas fases 1 e 2 após 24 e $48 \mathrm{~h}$. Entre os grupos experimentais, não foram constatadas diferenças significativas. Conclui-se que as soluções de própolis a $11 \%, 20 \%$ e $30 \%$ tiveram a mesma ação antimicrobiana, o que justifica a indicação daquela com menor concentração. Constatou-se também a mesma ação farmacológica em comparação aos anti-sépticos industrializados testados.
\end{abstract}

Unitermos: Própolis, abelha, saliva, microrganismos, metabolismo.

\begin{abstract}
Study, in vitro and ex vivo, of the action of different concentrations of propolis extracts against microorganisms present in human saliva". This study evaluated in vitro and ex vivo, the action of propolis extracts in different concentrations, in comparison with the effectiveness of oral antiseptics, against microorganisms present in human saliva. For in vitro experiences, glucose $25 \%$ solution was added to saliva, then individual samples were collected to prepare a control group $(\mathrm{C})$ and experimental groups (Exp), with addition of propolis extracts in $11 \%, 20 \%$ and $30 \%$, and extracts of Periogard, Listerine, Malvatricin e Parodontax. For ex vivo experiments, samples of saliva in fast and after mouthrinses with extracts of propolis $11 \%, 20 \%$ and $30 \%$ were collected and later glucose solution was added. In both phases of the experiments, successive samples of the mixtures were collected and glucose consumption by microorganisms present in human saliva was determined by the glucose oxidase method in 0,24 and $48 \mathrm{~h}$ of incubation preserved at $37{ }^{\circ} \mathrm{C}$. The values obtained in control group proved that there was consumption of glucose by microorganisms after 24 and $48 \mathrm{~h}$ of incubation in both phases of the study. However, among experimental groups no significant differences have been observed. We conclude that the propolis $11 \%, 20 \%$ and $30 \%$ solutions showed the same antimicrobial action. As a result, it is justified to recommend the use of the $11 \%$ concentration. It was concluded that propolis had similar pharmacological effect when compared to the industrialized oral antiseptics tested.
\end{abstract}

Keywords: Propolis, bee, saliva, microorganisms, metabolism.

\section{INTRODUÇÃO}

De origem grega, a palavra própolis resulta da combinação entre as expressões pró (defesa) e polis (cidade). As abelhas têm na própolis a garantia de assepsia no interior da colméia onde convivem em espaço restrito mais de setenta mil indivíduos com as crias e seu estoque de alimentos (Marcucci, 1996).
O interesse pela ação farmacológica de produtos naturais tem crescido e encontrado significativa aceitação popular. Dentre esses produtos, a própolis tem se destacado devido à sua aplicabilidade na indústria de alimentos e cosméticos, por ser utilizada como princípio ativo em vários produtos, dentre os quais os dentifrícios e os cremes para pele. Isso se deve às suas diversas propriedades terapêuticas, quais sejam: antimicrobiana, 
anti-tumoral, anestésica, anti-inflamatória e anti-viral (Ikeno et al., 1991; Marcucci, 1995; Duarte et al., 2003; Soares et al., 2006; Tavares et al., 2006; Longhini et al., 2007; Packer \& Luz, 2007).

A própolis é uma substância rígida, quebradiça quando fria e que se torna dúctil e maleável quando aquecida. Sua coloração é dependente da vegetação presente no local de extração pelas abelhas operárias, do tipo e do tempo de coleta. Assim, pode apresentar tonalidades que variam entre o marrom escuro e o marrom avermelhado ou esverdeado (Marcucci, 1995; Sousa et al., 2007).

As abelhas de várias espécies coletam a própolis de diversas partes das plantas como brotos, botões florais e exsudatos resinosos, e a enriquece com secreções salivares, principalmente, pela presença da enzima glicosidase, responsável pela hidrólise dos flavonóides glicosilados em agliconas (Burdock, 1998). A composição química da própolis agrega, basicamente, resinas e bálsamos aromáticos $(50 \%)$, ceras $(25 \%$ a $35 \%$ ), óleos essências (10\%), grãos de pólen ( $5 \%$ ), além de compostos fenólicos (flavonóides e ácidos fenólicos) minerais e vitaminas (Ferreira et al., 1996).

As propriedades da própolis estão diretamente relacionadas à sua composição química, o que se constitui no principal desafio para o seu uso em fitoterapia, tendo em vista que a sua composição varia de acordo com a vegetação da região, a época da coleta e a técnica empregada, bem como em função da espécie da abelha e do grau de africanização da Apis mellifera no Brasil, fatores importantes na definição das suas propriedades físicas, químicas e biológicas (Pereira et al., 2002).

Park et al. (2000) identificaram e classificaram 12 tipos de própolis no Brasil, de acordo com as características químicas deste produto natural. Preliminarmente, a própolis foi classificada de acordo com sua procedência, ou seja, em função da região onde era coletada. Entretanto, ao se constatar que a própolis de um mesmo tipo - portanto com características químicas similares, poderia ser encontrada em diferentes regiões, passou-se a classificá-la de acordo com o perfil revelado por esse produto através da cromatografia em camada delgada (CCD), e não mais com base no local original da coleta.

Estudos in vitro demonstram a ação antimicrobiana da própolis frente aos diversos microrganismos patogênicos bucais. Vários componentes da própolis têm sido analisados em diferentes países, sendo o ácido caféico, o éster fenetílico do ácido caféico (CAPE) e os flavonóides são os principais responsáveis pelo poder antibiótico desta resina (Havsteen, 1983; Marcucci, 1996; Menezes, 2005).

Em face destas considerações, o objetivo do presente estudo foi avaliar a ação antimicrobiana da própolis frente aos microrganismos presentes na saliva total e estimulada de humanos, em duas fases de ensaios laboratoriais, conforme o desenho do protocolo experimental. Na fase 1 avaliou-se, in vitro, a ação de três diferentes concentrações do extrato de própolis em comparação com os produtos industrializados Periogard, Listerine, Malvatricin e Parodontax, enquanto que na fase 2 foi avaliada a ação, ex vivo, do extrato de própolis nas mesmas concentrações utilizadas na fase 1 , frente aos microrganismos que ocorrem na saliva.

\section{MATERIAL E MÉTODOS}

Para a realização desta pesquisa, de natureza experimental e laboratorial, foram selecionados 30 doadores de saliva, atendidas as exigências relativas às condições satisfatórias de saúde geral e, particularmente, de saúde bucal, ou seja: ausência de lesões de cárie e de periodontopatias; rigoroso controle de placa bacteriana e de possíveis sangramentos gengivais; não estarem em uso de aparelho ortodôntico e possuírem no mínimo, 24 dentes. Atendidas estas condições, os voluntários foram submetidos ao exame salivar para avaliação do fluxo e da capacidade de tamponamento dessa secreção (Krasse, 1998).

\section{Processo de obtenção da saliva}

Uma vez selecionados, os voluntários foram devidamente informados quanto aos objetivos e a metodologia traçados para a realização do presente trabalho, e após firmarem o Termo de Consentimento Livre Esclarecido, foram orientados a não realizar qualquer tipo de profilaxia oral a partir da última refeição realizada às $18 \mathrm{~h}$ da noite que antecedeu a coleta da saliva, previamente marcada com antecedência para a manhã do dia seguinte. Esta condição assegurou a ausência de profilaxia oral durante o período de 12 a $14 \mathrm{~h}$.

Os doadores compareceram ao Laboratório de Bioquímica Oral do Instituto de Ciências da Saúde da Universidade Federal da Bahia no horário prédeterminado para a coleta das amostras de saliva em recipientes esterilizados, devidamente acondicionados em banho de gelo moído, até o início das análises.

\section{Protocolo experimental}

Para a realização do presente estudo, foram avaliados os anti-sépticos e os extratos de própolis disponíveis no mercado da cidade de Salvador, estado da Bahia, de acordo com os dados explicitados no Quadro 1.

$\mathrm{Na}$ primeira fase, foi avaliada a ação, in vitro, dos extratos de própolis a $11 \%, 20 \%$ e $30 \%$, do Periogard, Listerine, Malvatricin e Parodontax. O protocolo experimental foi elaborado tendo-se como fundamentação a determinação do possível efeito antimicrobiano das diferentes concentrações do extrato de própolis, comparativamente aos enxagüatórios 
contendo os princípios ativos clorexidina, timol e tirotricina (Quadro 2), mediante o consumo de glicose pelos microrganismos presentes na saliva total $\mathrm{e}$ estimulada de humanos, avaliado nos tempos de incubação zero, 24 e $48 \mathrm{~h}$, sendo que para cada grupo foi utilizado o valor de $\mathrm{n}=10$.

Às amostras da saliva coletada em jejum adicionou-se a solução de glicose a $25 \%$, retirando-se dessa mistura as alíquotas que constituíram o grupo controle (C). A cada grupo experimental $\left(\operatorname{Exp}_{1 \mathrm{a}}, \operatorname{Exp}_{2 \mathrm{a}}\right.$ $\operatorname{Exp}_{3 \mathrm{a},} \operatorname{Exp}_{4 \mathrm{a},} \operatorname{Exp}_{5 \mathrm{a}}, \operatorname{Exp}_{6 \mathrm{a}}$ e $\left.\operatorname{Exp}_{7 \mathrm{a}}\right)$ foi adicionado o respectivo extrato de própolis ou o anti-séptico Periogard, Listerine, Malvatricin ou Parodontax.

Em seguida, o grupo controle e os grupos experimentais foram incubados a $37{ }^{\circ} \mathrm{C}$, durante $48 \mathrm{~h}$, em estufa bacteriológica termo-regulável, em aerobiose, seguindo-se da retirada de sucessivas alíquotas para determinação do consumo de glicose pelo método da Glicose Oxidase, nos tempos $0,24,48 \mathrm{~h}$ e expressos os valores encontrados em $\mathrm{mg} / \mathrm{dL}$.

$\mathrm{Na}$ segunda fase das experimentações realizadas ex vivo, visando à determinação da atividade anti-bacteriana dos extratos de própolis a $11 \%, 20 \%$, $30 \%$, foram coletadas as amostras de saliva de cada voluntário, atendidas as mesmas condições estabelecidas na fase 1. Após a reserva de alíquotas desse fluido para a realização dos ensaios com o grupo controle $(\mathrm{C})$, os doadores foram divididos em três grupos, de acordo com a concentração do extrato de própolis utilizado no enxágüe bucal (Quadro 3).

Concluída a primeira coleta, os voluntários realizaram o enxágüe durante um minuto com o respectivo extrato de própolis diluído em água, de acordo com as normas do fabricante. Após o bochecho foi coletada a segunda amostra de saliva, constituindo-se dessa forma, os grupos experimentais $\operatorname{Exp}_{1 \mathrm{~b}}, \operatorname{Exp}_{2 \mathrm{~b}}, \operatorname{Exp}_{3 \mathrm{~b}}$ de acordo com a natureza de cada extrato: $11 \%, 20 \%$ e $30 \%$. Tanto às amostras da saliva influenciada pela própolis quanto à saliva que constituiu o grupo controle foi adicionada a solução de glicose a $25 \%$, seguindo-se da imediata coleta de alíquotas de cada grupo para determinação da taxa de glicose residual no tempo zero de experimentação. Novas dosagens de glicose residual foram realizadas em alíquotas retiradas dos grupos controle e experimentais após 24 e $48 \mathrm{~h}$ de incubação a $37^{\circ} \mathrm{C}$.

\section{RESULTADOS}

Após tratamento estatístico, os resultados das experimentações que constituíram o protocolo dos dois estudos - primeira e segunda fase, são apresentados através das respectivas médias e erros padrões (EPM). As médias dos diversos grupos foram comparadas através análise da variância (ANOVA) de medidas repetidas, seguindo-se da aplicação do teste paramétrico de Bonferroni.

De acordo com o protocolo experimental, avaliou-se na primeira fase do presente estudo, a eficácia dos extratos de própolis comercializados a $11 \%$, $20 \%$ e $30 \%$, comparativamente à ação dos produtos industrializados - Periogard, Listerine, Malvatricin e Parodontax.

Face aos resultados obtidos nessa fase (Tabela 1) (Gráfico 1), ao serem comparados os valores de glicose residual correspondentes ao grupo controle, no qual não houve adição de enxagüatório algum, no tempo $0 \mathrm{~h}$ de incubação a $37^{\circ} \mathrm{C}$ e nos intervalos de 24 e 48 $\mathrm{h}$, constatou-se ter havido diferença estatisticamente significativa nesses espaços de tempo.

Nos grupos experimentais $\operatorname{Exp}_{1 \mathrm{a}}, \operatorname{Exp}_{2 \mathrm{a}}, \operatorname{Exp}_{3 \mathrm{a}}$ $\operatorname{Exp}_{4 \mathrm{a}}, \operatorname{Exp}_{5 \mathrm{a}} \operatorname{Exp}_{6 \mathrm{a}}$ e $\operatorname{Exp}_{7 \mathrm{a}}$, ao serem confrontados os valores médios das taxas de glicose residual obtidas nos tempos, 0, 24 e 48h, não foram constatadas diferenças estatisticamente significantes, ao serem comparados os resultados obtidos nesses três tempos de incubação (Tabela 1) (Gráfico 1).

Na segunda fase desse estudo realizado ex vivo, avaliou-se a eficácia dos extratos de própolis a 11\%, 20 $\%$ e $30 \%$ frente aos microrganismos presentes na saliva total de humanos, conforme os dados explicitados na Tabela 2 e no Gráfico 2. Pôde-se constatar que houve diferenças estatisticamente significativas entre as médias do grupo controle nos três tempos de incubação, enquanto que, nos grupos experimentais, não foram constatadas diferenças significantes do ponto de vista estatístico, ao se fazer a comparação das médias atribuídas à concentração da glicose residual, obtidas nos tempos 0,24 e $48 \mathrm{~h}$, independente da concentração dos extratos da própolis utilizados, ou seja, 11\%, 20\% ou $30 \%$.

\section{DISCUSSÃO}

Nos diferentes tempos de experimentação constatou-se nos grupos controle constituintes da primeira e segunda fase do estudo que houve consumo de glicose pelos microrganismos presentes na saliva total e estimulada de humanos. De acordo com dados da literatura científica, os microrganismos utilizam a glicose com a finalidade de produzir polissacarídeos de reserva, de colonização e aderência, assim como para obter energia, o que resulta, conseqüentemente, na produção de ácidos, dentre os quais o lático, responsáveis pela desmineralização do esmalte dental, particularmente nas fases de sub-saturação iônica da saliva (Araújo et al., 1996).

No tocante à ação dos enxagüatórios bucais à base de própolis, a análise dos resultados dos grupos experimentais das fases 1 e 2 indicou não ter havido consumo de glicose algum. Tal constatação confirma que esse produto possui ação antimicrobiana contra os patógenos bucais (Ota \& Valente, 1998; Pamplona, 1997). Portanto, os resultados obtidos estão de acordo com a ação antibacteriana da própolis in vitro, sobre 
Quadro 1. Extratos de própolis e enxaguatórios.

\begin{tabular}{|lllc|}
\hline \multicolumn{1}{|c}{ Enxaguatório } & \multicolumn{1}{c}{ Fabricante } & \multicolumn{1}{c}{ Principio Ativo } & Concentração \\
\hline Extrato de própolis & NaturApi Produtos Naturais e Apícolas Ltda. & Extrato seco de própolis & $11 \%$ \\
Extrato de própolis & Apis Flora Ind. e Com. Ltda. & Extrato seco de própolis & $20 \%$ \\
Extrato de própolis & Herbarium Laboratório Botânico Ltda & Extrato seco de própolis & $30 \%$ \\
Periogard & Colgate - Palmolive. Divisão da Kolynos do & Digluconato de clorexidina & $0,12 \%$ \\
& Brasil LTDA. & Timol & $0,640 \%$ \\
Listerine & Warner-Lambert Co. Morris Plains & Eucaliptol & $0.092 \%$ \\
& & Salicilato de metila & $0,060 \%$ \\
& & Mentol & $0,042 \%$ \\
Malvatricin & Laboratório Daudt Oliveira Ltda. & Quinosal & $15 \mathrm{mg}$ \\
& & Tirotricina & $1,50 \mathrm{mg}$ \\
Parodontax & Smithkline Beecham Consumer Healtcare Reino & Gluconato de clorexidina & $0,005 \mathrm{~mL}$ \\
& Unido & & $0,20 \%$ \\
\hline
\end{tabular}

Quadro 2. Fase 1: Grupos controle e experimentais.

\begin{tabular}{|lcc|}
\hline \multicolumn{1}{|c}{ Produto } & $\mathrm{n}$ & Grupos \\
\hline Sem enxagüatório & 10 & $\mathrm{C}$ \\
Extrato de própolis a $11 \%$ & 10 & $\operatorname{Exp}_{1 \mathrm{a}}$ \\
Extrato de própolis a $20 \%$ & 10 & $\operatorname{Exp}_{2 \mathrm{a}}$ \\
Extrato de própolis a $30 \%$ & 10 & $\operatorname{Exp}_{3 \mathrm{a}}$ \\
Periogard & 10 & $\operatorname{Exp}_{4 \mathrm{a}}$ \\
Malvatricin & 10 & $\operatorname{Exp}_{5 \mathrm{a}}$ \\
Listerine & 10 & $\operatorname{Exp}_{6 \mathrm{a}}$ \\
Parodontax & 10 & $\operatorname{Exp}_{7 \mathrm{a}}$ \\
\hline
\end{tabular}

Quadro 3. Fase 2: Grupos controle e experimentais.

\begin{tabular}{|lcc|}
\hline \multicolumn{1}{|c}{ Produto } & $\mathrm{n}$ & Grupos \\
\hline Antes do enxágüe & 10 & $\mathrm{C}$ \\
Extrato de própolis a $11 \%$ & 10 & $\operatorname{Exp}_{1 \mathrm{~b}}$ \\
Extrato de própolis a $20 \%$ & 10 & $\operatorname{Exp}_{2 \mathrm{~b}}$ \\
Extrato de própolis a $30 \%$ & 10 & $\operatorname{Exp}_{3 \mathrm{~b}}$ \\
\hline
\end{tabular}

a microbiota bucal, representada particularmente pelos Streptococcus sobrinus; Streptococcus mutans; Streptococcus cricetus; Staphylococcus aureus; Staphyloccus epidermides; Streptococcus mutans; Lactobacillos sp; Candida albicans; Candida tropicalis; Prevotella intermedia; Prevotella melaninogenica; Porphyromonas gingivalis; Actinobacillus actinomycetemcomitans; Capnocytophaga gingivalis e Fusobacterium nucleatum. Há que se considerar que ao inibir a atividade da glucosiltransferase, a própolis exerce a atividade anti-bacteriana, uma vez que compromete a biossíntese de glucanos, conforme se referem diversos pesquisadores (Koo et al., 2000; Park et al.1998; Ota \& Valente, 1998).

O fato das propriedades biológicas da própolis estarem diretamente relacionadas à sua composição química que varia com o tipo de vegetação da região, a época da coleta, a técnica empregada, a espécie da abelha e o grau de africanização da Apis mellifera no
Tabela 1. Fase 1: Médias e EPM das dosagens de glicose (mg/ dL).

\begin{tabular}{c|c|c|c}
\hline Tempo & $0 \mathrm{~h}$ & $24 \mathrm{~h}$ & $48 \mathrm{~h}$ \\
\hline $\mathrm{C}$ & $253.4 \pm 6.10$ & $222.3 \pm 4.18$ & $205.9 \pm 4.80$ \\
$\operatorname{Exp}_{1 \mathrm{a}}$ & $271.0 \pm 9.18$ & $270.2 \pm 9.54$ & $269.3 \pm 8.24$ \\
$\operatorname{Exp}_{2 \mathrm{a}}$ & $264.5 \pm 3.43$ & $257.9 \pm 3.54$ & $232.7 \pm 5.98$ \\
$\operatorname{Exp}_{3 \mathrm{a}}$ & $240.7 \pm 3.73$ & $246.4 \pm 6.18$ & $221.2 \pm 6.20$ \\
$\operatorname{Exp}_{4 \mathrm{a}}$ & $267.5 \pm 11.36$ & $251.9 \pm 14.27$ & $248.0 \pm 8.21$ \\
$\operatorname{Exp}_{5 \mathrm{a}}$ & $252.5 \pm 14.88$ & $240.9 \pm 13.79$ & $240.0 \pm 7.26$ \\
$\operatorname{Exp}_{6 \mathrm{a}}$ & $260.4 \pm 12.38$ & $251.5 \pm 12.99$ & $248.2 \pm 10.17$ \\
$\operatorname{Exp}_{7 \mathrm{a}}$ & $247.1 \pm 14.36$ & $242.8 \pm 14.87$ & $243.9 \pm 12.33$ \\
\hline
\end{tabular}

C: grupo controle; $\operatorname{Exp}_{1 \mathrm{a}}$ extrato de própolis a $11 \%$; $\operatorname{Exp}_{2 \mathrm{a}}$ : extrato de própolis a $20 \%$; $\operatorname{Exp}_{3 a}$ : extrato de própolis a $30 \%$; $\operatorname{Exp}_{4 \mathrm{a}}$ : Periogard; $\operatorname{Exp}_{5 \mathrm{a}}$ : Listerine; $\operatorname{Exp}_{6 \mathrm{a}}$ : Malvatricin; $\operatorname{Exp}_{7 \mathrm{a}}$ : Parodontax, $p<0,05$.

Brasil, induz a se admitir que a ação antimicrobiana está intimamente relacionada à concentração de flavonóides e ácido cafeico, e mais especificamente, em se tratando da própolis tipo 6 (Mata Atlântica), com a concentração de compostos apolares (Pereira et al., 2002; Sforcin et al., 2001).

Os flavonóides e o CAPE são compostos fenólicos que possuem a capacidade de inibir o crescimento e a divisão celular, aumentar a permeabilidade da membrana e interferir na motilidade celular dos microrganismos. O ácido caféico e o CAPE além de possuírem ação antimicrobiana, são substâncias que podem desencadear reações alérgicas, como a dermatite de contato, e queimaduras, apesar dessas reações ocorrerem com baixa freqüência (Swerts et al., 2002). Este dado sinaliza a importância do uso desses produtos em concentrações baixas na constituição dos enxaguatórios bucais, uma vez preservada sua eficácia, 


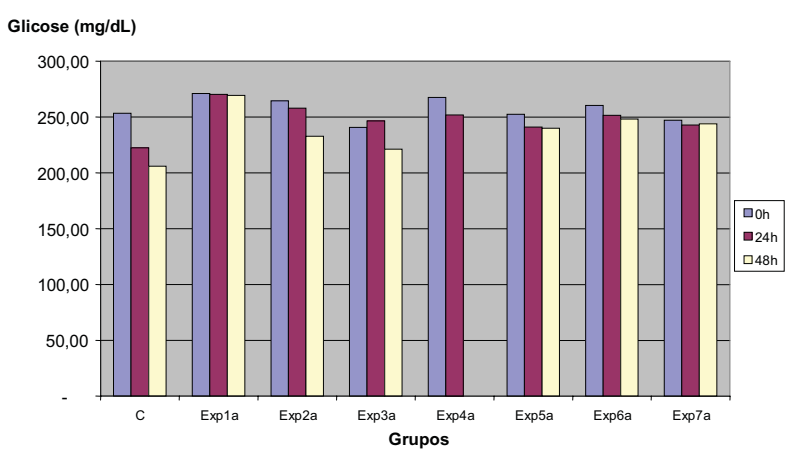

Gráfico 1. Fase 1: Taxas médias das dosagens de glicose (mg/ dL).

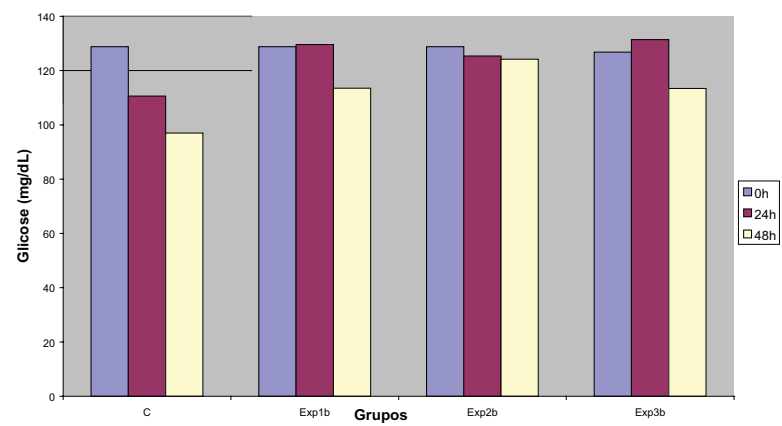

Gráfico 2. Fase 2: Taxas das médias das dosagens de glicose (mg/dL).

Tabela 2. Fase 2: Médias e EPM das dosagens de glicose (mg/ dL).

\begin{tabular}{c|c|c|c}
\hline Trupo & $0 \mathrm{~h}$ & $24 \mathrm{~h}$ & $48 \mathrm{~h}$ \\
\hline $\mathrm{C}$ & $128.8 \pm 1.22$ & $110.6 \pm 1.32$ & $97.0 \pm 1.32$ \\
$\operatorname{Exp}_{1 \mathrm{~b}}$ & $128.8 \pm 1.90$ & $129.6 \pm 1.45$ & $113.5 \pm 5.55$ \\
$\operatorname{Exp}_{2 \mathrm{~b}}$ & $128.8 \pm 2.52$ & $125.4 \pm 3.33$ & $124.2 \pm 3.47$ \\
$\operatorname{Exp}_{3 \mathrm{~b}}$ & $126.8 \pm 1.05$ & $131.4 \pm 3.41$ & $113.4 \pm 3.13$
\end{tabular}

C: grupo controle; $\operatorname{Exp}_{1 b}$ : saliva coletada logo após o enxágüe com própolis a $11 \%$ com adição de glicose a $25 \%$; $\operatorname{Exp}_{2 b}$ : saliva coletada logo após o enxágüe com própolis a $20 \%$ com adição de glicose a $25 \%$; $\operatorname{Exp}_{3 b}$ : saliva coletada logo após o enxágüe com própolis a $30 \%$ com adição de glicose a $25 \%, p<0,05$.

conforme ficou demonstrado no presente trabalho. Quanto aos compostos apolares presentes na própolis do tipo 6, sabe-se apenas que sua ação principal é antimicrobiana. Necessário se faz a realização de novos estudos visando avaliar a ação farmacológica desses compostos apolares no metabolismo dos microrganismos presentes na boca (Ota \& Valente, 1998; Pamplona, 1997).

Os ensaios com os extratos de própolis a $11 \%$,
$20 \%$ e $30 \%$ não revelaram diferenças estatisticamente significantes, evidenciando que a partir da concentração de $11 \%$, os extratos de própolis possuem ação antimicrobiana, corroborando dessa forma com os estudos de Pereira et al. (2002) que ao recomendarem a comercialização de própolis na concentração de $11 \%$ do extrato seco, confirmaram as normas preconizadas pelo Ministério da Agricultura.

Com base nos resultados do presente estudo, pode-se admitir que muito embora os extratos de própolis tenham composições heterogêneas, provavelmente esta heterogeneidade parece não influenciar negativamente a atividade anti-bacteriana, independente da concentração da própolis, se a $11 \%, 20 \%$ ou $30 \%$, uma vez que os extratos utilizados possuíam diferentes composições entre si, em virtude das suas procedências. $O$ fato dos fabricantes não informarem a composição desses produtos indica a importância da realização de estudos bioquímicos que tenham por finalidade explicitá-los para que se possa usufruir dos benefícios desse produto natural, tendo-se em conta sua prescrição nas mais baixas concentrações, ou a indicação de extratos mais concentrados, desde que seja justificável sua indicação em função da ação terapêutica dos seus componentes. Portanto, faz-se necessária uma rigorosa avaliação e ampla divulgação da composição da própolis a ser comercializada em função de sua procedência e a concentração de seus princípios ativos com o intuito de se assegurar as propriedades terapêuticas, dentre as quais se destacam a antimicrobiana, a anti-tumoral, a anestésica e a anti-inflamatória (Swerts et al., 2005).

Os extratos de própolis a $11 \%, 20 \%$ e $30 \%$ revelaram inibição do consumo de glicose, de modo semelhante aos produtos industrializados Listerine, Malvatricin, Parodontax e Periogard, largamente utilizados como antissépticos bucais (Swerts et al., 2002; Swerts et al., 2005). Há de se enfatizar que a própolis possui a vantagem de ser um produto natural, com maior diversidade molecular, ou seja, possui inúmeras substâncias terapêuticas compatíveis com o metabolismo dos mamíferos em geral, o que reduz a possibilidade de causar reações adversas aos tecidos bucais, em comparação aos produtos industrializados testados (Swerts et al., 2005)

Por fim é recomendável a realização de outros desenhos experimentais para que seja definido o período de utilização desse produto como enxagüatório bucal, sua posologia, possíveis reações colaterais, além de sua real eficácia sobre a placa dental em pacientes predispostos à carie dental, às periodontopatias ou a outras enfermidades infecciosas que possam acometer a cavidade bucal.

\section{CONCLUSÕES}

Diante dos resultados revelados pela própolis frente à saliva total e estimulada de humanos, e as 
condições de experimentação realizadas in vivo e ex vivo, pode-se concluir que os extratos de própolis a $11 \%, 20 \%$ e $30 \%$ apresentam a mesma eficácia antimicrobiana. O extrato de própolis a $11 \%$ parece ser o mais indicado, devido à sua eficácia antimicrobiana conjugada com a mais baixa concentração. Os extratos de própolis a $11 \%$, $20 \%$ e $30 \%$ apresentam a mesma eficácia antimicrobiana, comparativamente à ação dos produtos industrializados Parodontax, Periogard, Listerine e Malvatricin.

\section{REFERÊNCIAS}

Araújo MTB, Araújo RPC, Azevedo-Júnior PA, Campos EJ, Garcia MAS, Araújo CB 1996. Determinaçäo in vitro do grau de desmineralizaçäo do fosfato tricálcio em decorrência da açäo acidogênica dos microrganismos presentes na saliva humana em conseqüência da adiçäo do esteviosídeo e do aspartame. Rev ABO Nac 3: 377-381

Burdock GA 1998. Review of the biological properties and toxicity of bee propolis. Food Chem Toxicol 36:347363.

Duarte S, Koo H, Bowen WH, Hayachibara MF Cury JA, Ikegaki M, Rosalen PL 2003. Effect of a novel type of propolis and its chemical fractions on glucosyltransferases and on growth and adherence of Mutans Streptococci. Biol Pharm. 26: 527-531.

Ferreira RC, Valente PHM, Barbosa AD 1996. Atividade antibacteriana da propolis. Lecta-USF 14: 65-93.

Havsteen B 1983. H.Flavonoids, A class of natural products of high pharmacological potency. Biol Pharm 32: 1141-1148.

Ikeno K, Ikeno T, Miyazawa C 1991. Effects of propolis on dental caries in rats. Caries Res 25: 347-351.

Koo H, Smith AM, Vacca B, William H, Rosalen PL, Cury JA, Park YK 2000 Effects of Apis mellifera propolis on the activities of streptococcal glucosyltransferases in solution and adsorbed onto saliva-coated hydroxyapatite. Caries Res. 34: 418-426.

Krasse B.1998. Risco de cárie: um guia prático para avaliação e controle. Quintessence. 10: 113.

Longhini R, Raksa SM, Oliveira ACP, Svidzinski TIE, Franco SL 2007. Obtenção de extratos de própolis sob diferentes condições e avaliação de sua atividade antifúngica. Rev Bras Farmacogn 17: 388-395.

Marcucci MC 1995. Propolis-chemical-composition, biological properties and therapeutics activity. Apidologie. 26: 83-99.

Marcucci MC 1996. Propriedades biológicas e terapêuticas dos constituintes químicos da própolis. Quim Nova. 19: 529-535.

Menezes H 2005. Própolis: uma revisão dos recentes estudos de suas propriedades farmacológicas. Arq. Inst. Biol. 72: 405-441.

Ota C, Valente P 1998. Atividade da própolis sobre as bactérias isoladas da cavidade bucal. Lecta-UFS. 16: 73-77.

Packer JF, Luz MMS 2007. Método para avaliação e pesquisa da atividade antimicrobiana de produtos de origem natural. Rev Bras Farmacogn 17: 102-107.

Pamplona B. 1997. Propolis: composição e atividades terapeuticas. Rev Racine 7: 49-53.

Park YK, Koo MH, Abreu JA, Ikegaki M, Cury JA, Rosalen PL 1998. Antimicrobial activity of propolis on oral microrganism. Curr Microbiol 36: 24-28.

Park YK, Ikegaki M, Alencar SM, Moura FF 2000. Evaluation of Brazilian propolis by both phisicochemical methods and biological activity. Honeybee Science 21: 85-90

Perreira ADS, Seixas FRMS, Neto FRDA 2002. Propolis: 100 anos de pesquisa e suas perspectivas futuras. Quim Nova 25: 321-326.

Sforcin JM, Fernandes-Júnior A, Lopes CAM, Funari SRC, Bankova V 2001. Seasonal effect of Brasilian propolis on Candida albicans and Candida tropicalis. J Venom Anim Toxins 7: 139-144.

Soares AKA, Carmo GC, Quental DP, Nascimento DF, Bezerra FAF, Moraes MO, Moraes MEA 2006. Avaliação da segurança clínica de um fitoterápico contendo Mikania glomerata, Grindelia robusta, Copaifera officinalis, Myroxylon toluifera, Nasturtium officinale, própolis e mel em voluntários saudáveis. Rev Bras Farmacogn 16: 447-454.

Sousa JPB, Furtado NAJC, Jorge R, Soares AEE, Bastos JK 2007. Perfis físico-químico e cromatográfico de amostras de própolis produzidas nas microrregiões de Franca (SP) e Passos (MG), Brasil. Rev Bras Farmacogn 17: 85-93.

Swerts MSO, Freitas E, Silva DS, Maldonado DV, Totti da Costa JM, Medeiros UV 2002. Atividade antimicrobiana da própolis sobre bactérias bucais. JBE 3: 256-261.

Swerts MSO, Costa AMDD, Firini JE 2005. Associação de clorexidina e própolis atuando na inibição da aderência de Stretococcus spp. Revista Internacional de Periodontia Clínica 2: 10-16.

Tavares JP, Martins IL, Vieira AS, Lima FAV, Bezerra FAF, Moraes MO, Moraes MEA 2006. Estudo de toxicologia clínica de um fitoterápico a base de associações de plantas, mel e própolis. Rev Bras Farmacogn 16: 350-356. 